whilst the topography of the countryside often offers considerable obstacles to easy or rapid travelling. The young British forest officer minds none of those things. But knowledge, a trained staff, plenty of time (which entails much larger staffs), and an adequate equipment are required if the figures obtained for the total forest resources of the Empire (even for merchantable timber) are to be of a practical value. We find no reference to this part of the problem in the report under review.

The suggestion for co-operation amongst the owners of woods in Great Britain for improving their woodlands and in marketing the produce are to the point; also on the important subject of the introduction of new Empire hardwoods on to the home markets. In this latter matter the forest officer is practically powerless. It is a question for the timber merchant, and as the writers of the report rightly say, the introduction of new timbers "involves risk and expense which exporters, with or without Government aid, must be prepared to undertake" ; and they add: "We advocate a policy of restraint in regard to the number of varieties of new Empire timbers which are concurrently introduced into the British market.'

This report is a valuable piece of work, covers a wide range of outlook in the timber problems of the British Empire, and its perusal may be strongly recommended to all who are in any way interested in timber supplies.

\title{
The Four Component System in Peace and War.
}

$\mathrm{D}^{\mathrm{n}}$

R. F.A. FREETH, of Imperial Chemical Industries, Ltd., honorary lecturer in the theory and practice of heterogeneous equilibria at University College, London, gave his inaugural address on Friday, Mar. 1, on " The Four Component System in Peace and War."

The particular type of four component system with which Dr. Freeth dealt is known as the reciprocal salt pair, or as a double decomposition. One of the latest and best-known examples of this is the conversion saltpetre process, whereby potassium chloride and sodium nitrate are converted into potassium nitrate and sodium chloride. The subject was developed along the lines of Meyerhoffer, one of the pioneers of this field, who published his paper about thirty years ago, but the method of representation used to explain the original arguments was that developed by Prof. Janecke, of the Technical High School, Hanover.

The method of representation takes the form of a eube the base of which represents all the possible mixtures of the salts whilst water is plotted vertically. Considering the base of such a cube only, that is to say, the relative proportions of the salts, such base can be considered as being divided into four areas, each of which represents saturation with respect to one of the four salts under consideration. If by any means a solution can be obtained within an area representing saturation with respect to a particular salt, then generally speaking it is possible to obtain that salt in a pure condition.

The famous reciprocal salt pairs of commerce were then considered, particular attention being paid to the ammonia soda process which was developed in Great Britain by the late Dr. Ludwig Mond. Several other well-known working processes were also discussed, notably the caustification of sodium carbonate by lime giving caustic soda. All these old commercial processes were developed empirically, and it is generally found that current practice corresponds very closely with the optimum conditions predicted by a stringent theoretical treatment.

Reactions of this character played a very important part in the War. Fixed nitrogen is essential for modern explosives, both for propellants and for the high explosives used for bursting charges in shells. Until the War, the main source of fixed nitrogen was Chile nitre; treatment of this nitre with sulphuric acid yields nitric acid, which can be converted into high explosives like tri-nitro-toluene, propellants such as cordite, and by neutralisation with ammonia can be made to yield ammonium nitrate. Germany obviously could not depend indefinitely on the Chile supplies, so the Haber and the Ostwald processes were developed. The Haber process makes ammonia, using coke, air, and water as raw materials ; the Ostwald process, by burning ammonia with a limited quantity of oxygen, converts it into nitric acid. After these processes were once developed on a sufficiently large scale, Germany was àutomatically independent of any outside supplies of fixed nitrogen. Both processes, more especially the Haber process, required very considerable advances in technique.

On the outbreak of war in 1914 it soon became manifest that immense supplies of fixed nitrogen would be required by Great Britain. Even assuming that the productive capacity, making nitric acid on the old lines, would have been sufficient, there was a shortage of toluene for the necessary quantity of T.N.T. had that explosive been exclusively used. It was speedily discovered that T.N.T. could be diluted with no less than four times its weight of ammonium nitrate without impairing the high explosive properties of the mixture. The supply of ammonium nitrate, therefore, became of vital importance. Lord Moulton, the director of Explosive Supply, was faced with the following dilemma: Should he attempt to erect Haber and Ostwald plants of the necessary size, or should he attempt to make ammonium nitrate by double decomposition, using Chile nitrate as his source of fixed nitrogen? He decided on the latter course, for the very good reason that he considered the enormous calls on technical men of every kind rendered it almost out of the question to develop what was, in Great Britain, an entirely novel process.

Three double decomposition processes were used in the War period, and nearly all of them had been considered as technically impossible after practical trial. These processes were :

(1) The ammonia soda reaction on sodium nitrate giving ammonium nitrate and sodium bicarbonate. (2) Conversion of the waste calcium chloride of the ordinary ammonia soda process into calcium nitrate by double decomposition with sodium nitrate and the subsequent decomposition of the calcium nitrate with ammonium earbonate yielding ammonium nitrate and calcium carbonate. (3) Double decomposition of sulphate of ammonia and sodium nitrate giving ammonium nitrate and sodium sulphate. This latter process, after initial failure, afterwards became successful ; it was worked on a very large scale in Great Britain and upon a still larger scale in the United States. All these processes were developed both theoretically and practically in the research laboratories of Messrs. Brunner Mond and Co., Ltd., of which Dr. Freeth was the head.

Finally, Dr. Freeth paid tribute to the extraordinary help which those engaged in developing this process had received from theoretical work of the Dutch school, notably of Prof. Schreinemakers in Leyden, while the germ of all the theories involved goes back to a most distinguished American mathematical philosopherWillard Gibbs - probably one of the most detached men who ever lived.

No. 3097, VoL. 123] 